\title{
Unraveling the role of ectopic thymic tissue in patients undergoing thymectomy for myasthenia gravis
}

\author{
Feng Li ${ }^{1}$, Ya Tao ${ }^{2}$, Gero Bauer ${ }^{1}$, Aron Elsner ${ }^{1}$, Zhongmin $\mathrm{Li}^{1}$, Marc Swierzy ${ }^{1}$, Julianna Englisch ${ }^{1}$, \\ Andreas Meisel $^{3}$, Mahmoud Ismail $^{1}$, Jens-C. Rückert ${ }^{1}$ \\ ${ }^{1}$ Department of Surgery, Competence Center of Thoracic Surgery, Charité University Hospital Berlin, Berlin, Germany; ${ }^{2}$ Department of Obstetrics, \\ the First Affiliated Hospital of Zhengzhou University, Zhengzhou 450052, China; ${ }^{3}$ Department of Neurology Berlin, Charité University Hospital \\ Berlin, Berlin, Germany \\ Contributions: (I) Conception and design: JC Rückert, A Meisel, M Ismail, F Li; (II) Administrative support: All authors; (III) Provision of study \\ materials or patients: F Li, Y Tao, M Ismail, G Bauer, A Elsner, Z Li; (IV) Collection and assembly of data: F Li, Y Tao, J Englisch, M Swierzy; (V) \\ Data analysis and interpretation: All authors; (VI) Manuscript writing: All authors; (VII) Final approval of manuscript: All authors. \\ Correspondence to: Jens-C. Rückert, MD, PhD. Department of Surgery, Competence Center of Thoracic Surgery, Charité University Hospital Berlin, \\ Charitéplatz 1, 10117 Berlin, Germany. Email: jens-c.rueckert@charite.de.
}

\begin{abstract}
Extended thymectomy has been considered the goal of surgery for myasthenia gravis (MG) mainly due to the existence of ectopic thymic tissue. Recently, ectopic thymic tissue has attracted increasing attention in patients with MG following thymectomy. However, the specific role of ectopic thymic tissue in patients with MG is still under debate. A systematic search of the literature was performed on PubMed and Medline according to the Preferred Reporting Items for Systematic Reviews and Meta-Analyses (PRISM) statement. Studies evaluating the rate of ectopic thymic tissue in patients with MG with or without thymoma were included. Extraction was performed for all eligible studies and the rate of ectopic thymic tissue at common locations was calculated. Eighteen out of fifty-nine studies were eligible for inclusion, of which ten studies reported the common locations of ectopic thymic tissue in mediastinal fat. Of these ten studies, the presence of ectopic thymic tissue was investigated in different anatomical locations in 882 patients, of whom, 509 patients $(58 \%$ ) have at least one positive location with the most common ones being anterior mediastinal fat, pericardiophrenic angles, aortopulmonary window, cervical region (pretracheal fat) and lateral to phrenic nerves. On the other hand, nine studies analyzed the influence of the presence of ectopic thymic tissue on the clinical outcomes of MG patients. Of these, six found that the presence of ectopic thymic tissue in MG patients is a significant predictor of poor outcome after thymectomy, however, the other three did not find a significance. Altogether, ectopic thymic tissue is likely to present in more than a half of patients undergoing thymectomy for MG. Besides, MG patients who have ectopic thymic tissue after thymectomy do not seem to have as good outcome as those who have not.
\end{abstract}

Keywords: Myasthenia gravis (MG); ectopic thymic tissue; thymectomy

Submitted Feb 25, 2019. Accepted for publication Jul 02, 2019.

doi: $10.21037 /$ jtd.2019.08.109

View this article at: http://dx.doi.org/10.21037/jtd.2019.08.109

\section{Introduction}

Myasthenia gravis (MG) is an autoimmune disease due to the production of autoantibodies binding to acetylcholine receptors or other related molecules at the neuromuscular junction, thereby causing muscle weakness. The etiologies of MG are only partially understood, which includes genetic risk factors and thymic pathologies (1). Neoplastic, inflammatory and age-related thymus are likely involved in the immunopathogenesis of MG (2).

Thymectomy has become an indispensable treatment for patients with MG. From a historical perspective, surgical 
therapy for MG actually developed earlier than medications. In 1912, Schumacher and Roth first reported a 18-year-old woman with hyperthyroidism and MG who experienced improvement of myasthenia after a subtotal thyroidectomy through an incision in the neck (3). About two decades later in 1939, Blalock described a durable remission of MG after transsternal thymectomy (4). Later in 1941, Blalock further reported encouraging early results of six patients with MG after transsternal thymectomy and recommended a complete removal of all thymus tissue to alter the course of MG due to the presence of thymic abnormalities in patients with MG (5). Thereafter, median sternotomy became a widespread approach for thymectomy in the majority of thoracic surgery clinics except for several institutes where transcervical approach for thymectomy was preferred $(6,7)$, which opened up the discussion on radicality of thymectomy. Although ectopic foci of the thymic tissue was first described in 1912 by Wenglowski (8), it was not until in 1975 that Masaoka found high incidence of extracapsular thymic tissue in mediastinal fat, concluding that an extended resection with thymus and all mediastinal fat is necessary for patients with MG (9). Since then, many retrospective studies have been conducted to compare extended with limited resections in patients with MG, concluding that the more complete resection, the higher the remission rate $(10,11)$. Recently, the Myasthenia Gravis Thymectomy Trail (MGTX) first determined the therapeutic value of thymectomy in nonthymomatous $\mathrm{MG}(12,13)$. However, it is common knowledge that even total thymectomy does not result in complete stable remission in all patients. This might be partly due to ectopic tissue that is surgically inaccessible even through an aggressive approach (14). Removal of the residual thymus by reoperation can relieve the persistent symptoms after "partial" resections (15-20). Furthermore, ectopic thymic tissue was found in more than a half of the specimens after reoperations (20). Thus, ectopic thymic tissue seems to play an important role in patients with MG.

It is of importance to have a thorough knowledge of ectopic thymic tissue in patients with MG, thereby providing researchers and surgeons better chance to deal with it and improve the quality of care. Recently, Marx and colleagues have conducted a comprehensive review on ectopic thymic tissue and ectopic thymic tumors (21). Hereby, we aimed at providing an overview on the specific role of ectopic thymic tissue in MG patients focusing on the definition and identification, the prevalence and distribution and the clinical significance.

\section{Materials and methods}

A systematic search of the literature was performed on PubMed and Medline in September 2018 using iterations of the phrases to locate any studies reporting ectopic thymic tissue in patients with MG with or without thymoma. The systematic review was developed according to the Preferred Reporting Items for Systematic Reviews and Meta-Analyses (PRISM) statement (22). The review did not register at any website and a review protocol did not exist.

"(((ectopic thymic tissue) OR heterotopic thymic tissue)) AND ((((myasthenia gravis[Title/Abstract]) OR myasthenic syndrome[Title/Abstract]) OR neuromuscular disease[Title/ Abstract]) OR neuromuscular junction disease[Title/ Abstract])".

Fifty-nine studies were found and assessed for inclusion. The reference lists of the relevant studies were also searched for additional studies. At last, we included 18 studies that reported the rate of ectopic thymic tissue in patients with MG and summarized in Table 1.

\section{Results}

\section{Definition and identification}

Thymus is usually composed of multiple lobes, separately encapsulated, and anatomically located in the anterior superior mediastinum. Ectopic thymic tissue is frequently defined as the un-encapsulated lobules of thymus or microscopic foci of thymic tissue that are located outside the normal position, widely distributing in the mediastinal fat between the level of the thyroid and the diaphragm $(9,14,23,37)$. Recently, the role of "active ectopic thymic tissue" was introduced and defined as the presence of germinal center in the ectopic thymic tissue (37).

Several imaging techniques have been researched on the detection of ectopic thymic tissue preoperatively (40-43). Ectopic thymus can be visualized by ultrasound, computed tomography (CT) and magnetic resonance imaging (MRI) (40-42). However, their diagnostic role in detecting widely distributed ectopic thymic tissue in mediastinal fat is still lacking. Standardized uptake value (SUV) of perithymic region on positron emission tomography (PET) was reported to be correlated with the discovery of ectopic thymic tissue after thymectomy (43). Although it could be greatly helpful to locate possible ectopic thymic tissue preoperatively, data on the diagnostic accuracy of imaging techniques in ectopic thymic tissue imaging are still lacking. 


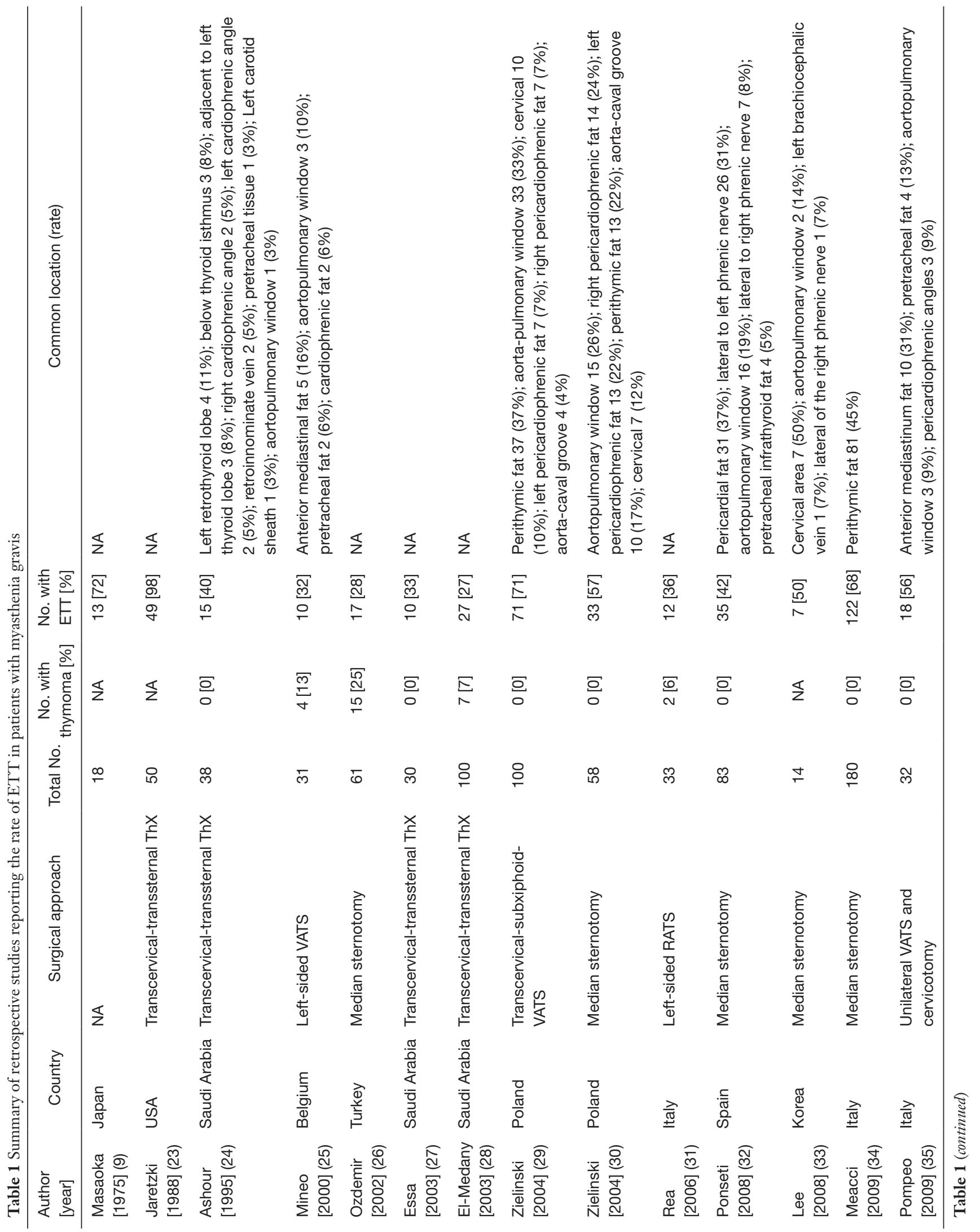




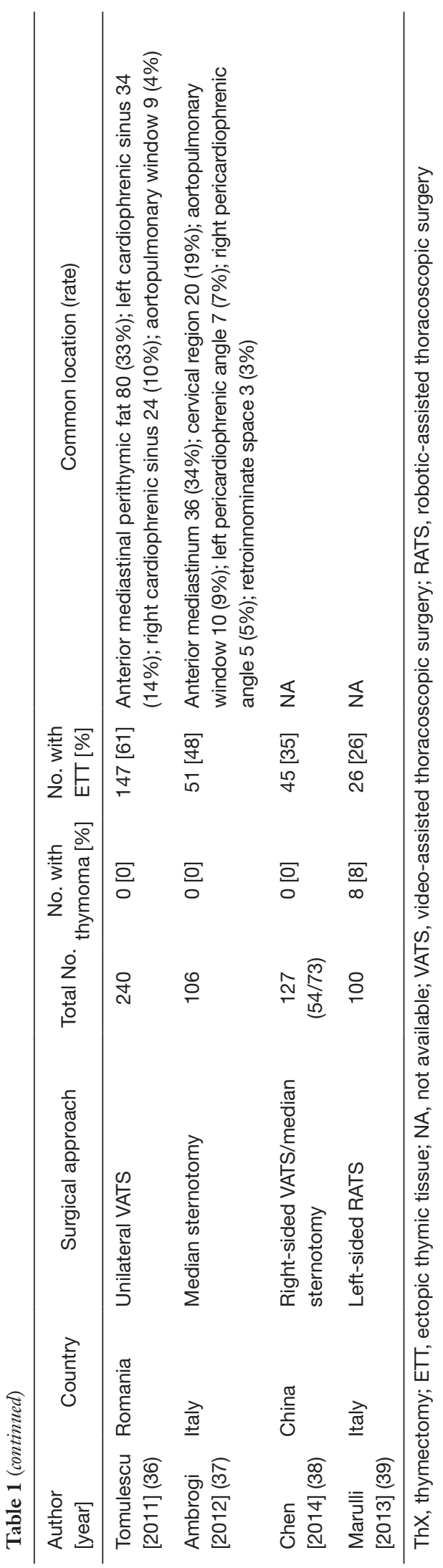

In pathological studies $(24,32,33,37)$, specimens were usually dissected and labeled by anatomical locations. Tissue fragments were embedded in paraffin block after fixed in $10 \%$ formalin. Then, tissue blocks were sliced and stained using hematoxylin and eosin. Ectopic thymic tissue was searched usually in 1 from every 5 tissue sections of fatty tissue. The diagnosis of ectopic thymic tissue was confirmed by the presence of the Hassals corpuscles. Moreover, in one study, Ambrogi and Mineo also used monoclonal antibodies against CD23 to assess the presence of the germinal centers, thereby demonstrating the presence of active ectopic thymic tissue (37).

\section{Prevalence and distribution}

Table 1 summarizes the prevalence and common locations of ectopic thymic tissue in patients with MG. The median rate of ectopic thymic tissue in patients with MG is $41 \%$ (range, 26-98\%) according to previous retrospective studies (Table 1). The range of the reported rate is quite wide, possibly due to different surgical procedures, methods of the histological investigation and the intensities of the workup. Ten out of 18 studies reported the common locations of ectopic thymic tissue in mediastinal fat $(24,25,29,30,32-37)$. Of these ten studies, 882 patients were studied on ectopic thymic tissue in different anatomical locations, of whom 509 patients (58\%) were positive. Unfortunately, the studied anatomical locations varied from one to another. The authors summarized and calculated the rates of ectopic thymic tissue in several commonly reported anatomical regions (Figure 1): anterior mediastinal perithymic fat 293 (33.2\%), pericardiophrenic angles 120 (13.6\%), aortopulmonary window $92(10.4 \%)$, cervical region (pretracheal fat): 66 (7.5\%), lateral to phrenic nerves 34 (3.9\%), aortocaval groove $14(1.6 \%)$, behind innominate vein $6(0.7 \%)$. It is worth mentioning that the authors categorized anterior mediastinal fat and perithymic fat from previous studies into anterior mediastinal perithymic fat in this review, and left retrothyroid lobe, below thyroid isthmus, adjacent to left thyroid lobe, pretracheal tissue, left carotid sheath, cervical region and pretracheal infrathyroid fat into cervical region (pretracheal fat). Then the rate of ectopic thymic tissue at each anatomical location was calculated as number of cases with ectopic thymic tissue at the anatomical location divided by number of cases evaluating the presence of ectopic thymic tissue at this anatomical location.

Interestingly, in a prospective autopsy study, ectopic thymic tissue was found in 32 out of 50 cadavers (64\%) 
after a two-stage resection (44). The researchers concluded that some anatomical locations with frequent presence of ectopic thymic tissue are hardly accessible to the firststage resection by "maximal" thymectomy. The inaccessible ectopic thymic tissue were frequently located along phrenic

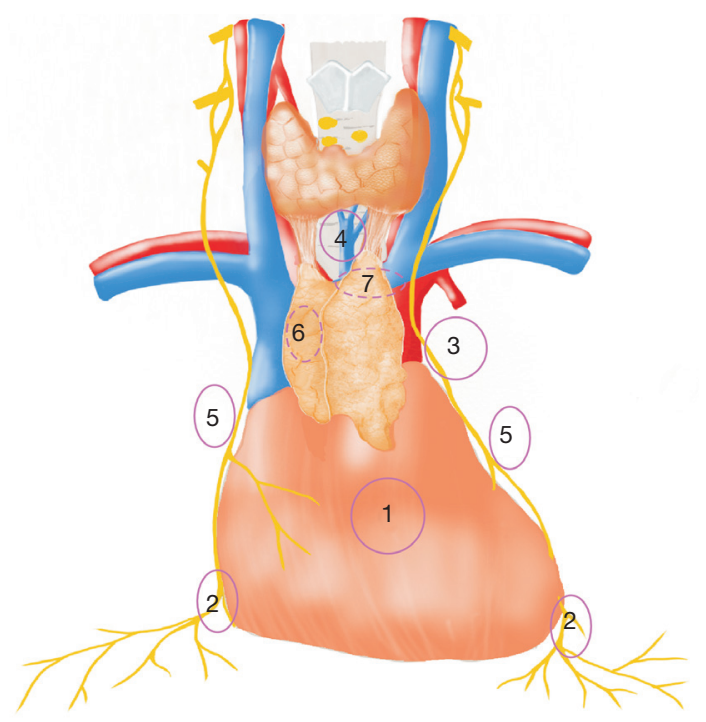

Figure 1 The rates of ectopic thymic tissue in common anatomic locations summarized from previous studies. 1, anterior mediastinal fat: 293 (33.2\%); 2, pericardiophrenic angles: 120 (13.6\%); 3 , aortopulmonary window: 92 (10.4\%); 4, cervical region (pretracheal fat): $66(7.5 \%)$; , lateral to phrenic nerves: 34 (3.9\%); 6 , aortocaval groove: $14(1.6 \%)$; 7 behind innominate vein: $6(0.7 \%)$. nerves with a rate of $32 \%$, predominantly at the left side. This is in line with what Mulder described in 1986: "the left lobe tends to merge laterally with the fatty tissue contiguous with the phrenic nerve" (45). This is why we favor the leftsided approach for robotic thymectomy in patients with nonthymomatous MG.

\section{Clinical significance}

Retrospective evidence has suggested a need for the resection of possible ectopic thymic tissue in mediastinal fat $(19,30,46,47)$. Importantly, many retrospective studies have shown that the presence of ectopic thymic tissue is significantly associated with the poor outcome of MG patients undergoing thymectomy (Table 2) (24,26-28,32,37). Unfortunately, the outcome measures have varied considerably, thus it is difficult to perform an integrated analysis of the prognostic role of ectopic thymic tissue in patients with MG.

In 1995, Ashour from King Khalid University hospital in Saudi Arabia first reported that the presence of ectopic thymic tissue is a significant predictor of poor outcome in patients with MG after transcervical-transsternal "maximal" thymectomy (24). The investigators from this institute defined complete remission as patients who were asymptomatic without medications. After a mean followup period of 14.5 months (range, 4-72 months), complete remission was noted in 11 out of 23 patients (48\%) without ectopic thymic tissue and in 2 out of 15 patients (13\%)

Table 2 Summary of findings from articles evaluating the clinical significance of ETT in myasthenia gravis

\begin{tabular}{|c|c|c|c|c|c|c|}
\hline Author [year] & Country & Surgical approach & Total No. & $\begin{array}{c}\text { No. with } \\
\text { thymoma [\%] }\end{array}$ & $\begin{array}{l}\text { No. with } \\
\text { ETT [\%] }\end{array}$ & $\begin{array}{c}\text { Clinical } \\
\text { significance }\end{array}$ \\
\hline Ashour [1995] (24) & Saudi Arabia & Transcervical-transsternal ThX & 38 & $0[0]$ & $15[40]$ & + \\
\hline Ozdemir [2002] (26) & Turkey & Median sternotomy & 61 & 15 [25] & $17[28]$ & + \\
\hline Essa [2003] (27) & Saudi Arabia & Transcervical-transsternal ThX & 30 & $0[0]$ & 10 [33] & + \\
\hline Zielinski [2004] (30) & Poland & Median sternotomy & 58 & $0[0]$ & $33[57]$ & - \\
\hline Ponseti [2008] (32) & Spain & Median sternotomy & 83 & $0[0]$ & 35 [42] & + \\
\hline Ambrogi [2012] (37) & Italy & Median sternotomy & 106 & $0[0]$ & $51[48]$ & + \\
\hline
\end{tabular}

+ means that the presence of ectopic thymic tissue is associated with poor outcome of myasthenia gravis after thymectomy. - means that the presence of ectopic thymic tissue is not associated with the clinical outcome of myasthenia gravis after thymectomy. ThX, thymectomy; ETT, ectopic thymic tissue; VATS, video-assisted thoracoscopic surgery; RATS, robotic-assisted thoracoscopic surgery. 
with ectopic thymic tissue (24). Later on in 2003, Essa and colleagues from the same institute reported another series of 30 children with MG who underwent thymectomy through the same surgical technique (27). One of 10 (10\%) children with ectopic thymic tissue reached complete remission at a mean follow-up time of 53.5 months (range, 9-180 months), whereas 12 of $20(60 \%)$ children without ectopic thymic tissue reached complete remission (27). In the same year, El-Medany and colleagues from the same center also reported the whole cohort of 100 myasthenic patients who underwent maximal thymectomy (28). Complete remission was observed in 5 out of 27 patients (18.5\%) with ectopic thymic tissue and 31 out of 73 patients $(42.5 \%)$ without ectopic thymic tissue after a mean follow-up period of 7.6 years (range 8 to 180 months) (28). Therefore, the investigators concluded that patients without ectopic thymic tissue are more likely to reach complete remission in comparison to patients with ectopic thymic tissue.

In 2003, Ozdemir and colleagues present the results of 61 patients with MG who underwent extended thymectomy through a median sternotomy (26). In this retrospective study, remission was defined as no symptoms without medications and improvement was defined as no or fewer symptoms with the same or less medications. After a median follow-up time of 46 months (range, 12-81 months), improvement or remission was noted in 10 out of 17 (58.8\%) patients with ectopic thymic tissue and 40 out of 44 (90.9\%) patients without ectopic thymic tissue. Multivariate analysis by logistic regression model indicated that the presence of ectopic thymic tissue is an independent predictor on clinical outcome in MG patients undergoing extended thymectomy.

In 2008, Ponseti and colleagues researched on the influence of ectopic thymic tissue on the clinical outcome of 83 seropositive generalized nonthymomatous $M G$ patients who underwent transsternal thymectomy (32). In this retrospective report, thirty-five patients ( $42 \%$ ) had ectopic thymic tissue. Clinical outcome was assessed according to Myasthenia Gravis Foundation of America (MGFA) post-intervention status. After a mean follow-up period of 88.4 months (range, 20-144 months), 33 patients (69\%) without ectopic thymic tissue obtained complete stable remission, whereas only nine patients $(26 \%)$ with ectopic thymic tissue did so. The probability of complete stable remission at 5 years was $65 \%$ in patients without ectopic thymic tissue and $26 \%$ in patients with ectopic thymic tissue.

In 2012, Ambrogi and Mineo retrospectively reviewed the presence of ectopic thymic tissue in patients with seropositive nonthymomatous MGFA classification III MG who underwent extended thymectomy (37). Ectopic thymic tissue was found in 51 of $106(48 \%)$ patients, of whom 34 patients $(67 \%)$ presented germinal centers (defined as active ectopic thymic tissue). Clinical outcome was assessed according to MGFA post-intervention status. In 96 patients with a mean follow-up period of $160 \pm 91$ months, ectopic thymic tissue and active ectopic thymic tissue were negatively associated with complete stable remission. Cox regression analysis demonstrated that the presence of active ectopic thymic tissue was the most significant negative predictor of complete stable remission.

On the other hand, some studies found no influence of the presence of ectopic thymic tissue on the clinical outcome of patients with MG after thymectomy (Table 2) $(25,30,39)$. According to Zielinski et al., however, this is possibly due to a complete resection of all fatty tissue in the mediastinum and the neck, which may result in a complete stable remission in patients with ectopic thymic tissue (30). Therefore, even though controversy still lies in the prognostic role of the presence of ectopic thymic tissue in patients with MG after thymectomy, results from the current literature have shed light on the importance of the removal of ectopic thymic tissue for the treatment of MG. From this point of view, the common locations of ectopic thymic tissue we summarized in this review might guide the resectional extent of thymectomy in the future clinical practice.

\section{Discussion}

It is likely that ectopic thymic tissue presents in more than half of the patients with MG and active ectopic thymic tissue presents in about $32 \%$ of them (Table 1). Although it can be found at any anatomical locations in both mediastinal and lower cervical fat, there seems to be some preferred sites. The distribution of active ectopic thymic tissue is still unclear. In addition, it takes a lot of time, money and efforts to address the ectopic thymic tissue and active ectopic thymic tissue, thus a well-designed prospective observational study should be of great value to provide high level of evidence. A comprehensive work-up from the MGTX group has been reported in detail, describing a perfect way of addressing the histopathology of thymectomy specimens $(48,49)$. The role of ectopic thymic tissue is currently being investigated and the results are eagerly awaited. We highly recommend that each institute should reference this procedure in the histological workup of thymectomy specimen.

Regarding the role of ectopic thymic tissue in patients with MG, it is possible that the persistent symptoms are 
due to an "incomplete" resection or surgical intervention cannot influence the course of MG in this population. However, there is no effective way to locate ectopic thymic tissue preoperatively, which makes it impossible to address this hypothesis. The authors recommend further imaging research taking the reported common locations of ectopic thymic tissue as the regions of interest, thereby possibly improving the diagnostic accuracy of different imaging techniques. Besides, novel imaging techniques should be developed or introduced, such as multifrequency magnetic resonance elastography (50) and deep learning (51), in thymus imaging. Furthermore, a prediction model by the characteristics of patients or the biomarkers from peripheral blood might also be helpful to predict the presence of ectopic thymic tissue in patients with MG.

Although the clinical significance of ectopic thymic tissue is controversial, previous studies have shed light on its potential role in MG. First, the autoantibody is likely produced in active ectopic thymic tissues, e.g., B-cell follicles and germinal centers (52-55). Germinal centers were frequently found in ectopic thymic tissue, which was defined as active ectopic thymic tissue (37). Importantly, the presence of active ectopic thymic tissue is also significantly associated with poor outcome of patients with MG after thymectomy (37). Furthermore, some studies do support that changes in acetylcholine receptor antibody titers parallel with the clinical changes after thymectomy $(56,57)$, although others do not $(58,59)$. Second, "the more complete the resection, the better clinical outcome" has become an international consensus of thymectomy $(60,61)$. On the other hand, ectopic thymic tissue was also found in more than a half of residual thymus after reoperations, which can relieve the persistent symptoms after the first partial resection (20). Third, even after exclusion of some subgroups such as congenital MG and MG seropositive for anti-muscle-specific kinase (MuSK) antibody $(62,63)$, extended thymectomy cannot result in complete stable remission in all selected patients for surgery. This is possibly due to an incomplete resection of all ectopic thymic tissue (44). Furthermore, other factors such as timing of surgery may also influence the effectiveness of thymectomy even with the resection of all ectopic thymic tissue. Latest findings on the distribution of the germinal centers inside MG patients of the MGTX trial gave further insight on the association between clinical outcome and timing of surgery, which is consistent with the conclusion drawn by Sir Keynes in 1949 (64). Prof. Alexander Marx, the investigator of the thymus histology study for the
MGTX trial, demonstrated (personal communication) that lymphocytes might migrate to bone marrow at a certain time after disease onset, which might diminish the influence of even most radical thymectomy on the improvement of MG. This might be another explanation for the remission rate being lower than $100 \%$ after extended thymectomy. All together, the retrospective evidence indicated that ectopic thymic tissue might be one of the factors that break the effectiveness of thymectomy in patients with MG.

Different surgical approaches for thymectomy should attempt to remove all tissue in the mediastinum and neck that might harbor ectopic thymic tissue. It is possible that different surgical approaches can achieve complete resection with improved technology and instruments. Further studies may prove the equivalence of different surgical approaches by investigating the prevalence of ectopic thymic tissue harvested at different anatomical locations. However, some anatomical sites might be difficult to access. For example, the tissue in cervical region should be managed by gently grasping and bringing down to get a complete resection. Besides, the contralateral pleura should be opened to completely dissect the cardiophrenic tissue. However, as the therapeutic value of thymectomy continues to increase and might become relevant for more subgroups of MG, immunosuppressive drug therapy is, at the time of writing, still the backbone in the management of MG. Most patients with MG require, for a certain time, immunosuppressive medications to control symptoms and improve the quality of life.

\section{Conclusions}

Ectopic thymic tissue is likely to present in more than a half of MG patients with the common locations being anterior mediastinal fat, pericardiophrenic angles, aortopulmonary window, cervical region (pretracheal fat) and lateral to phrenic nerves. So far, no imaging techniques can effectively locate the ectopic thymic tissue preoperatively. The clinical significance of ectopic thymic tissue is based on retrospective evidence and data on active ectopic thymic tissue are extremely limited, well-designed prospective observational studies are required to improve the evidence base, thereby improving the quality of care in patients with MG.

\section{Acknowledgments}

F Li is thankful to China Scholarship Council for the financial support during his study in Germany. 


\section{Footnote}

Conflicts of Interest: The authors have no conflicts of interest to declare.

Ethical Statement: The authors are accountable for all aspects of the work in ensuring that questions related to the accuracy or integrity of any part of the work are appropriately investigated and resolved.

\section{References}

1. Marx A, Willcox N, Leite MI, et al. Thymoma and paraneoplastic myasthenia gravis. Autoimmunity 2010;43:413-27.

2. Marx A, Pfister F, Schalke B, et al. The different roles of the thymus in the pathogenesis of the various myasthenia gravis subtypes. Autoimmun Rev 2013;12:875-84.

3. Roth S. Thymektomie bei einem Fall von Morbus Basedowii mit Myasthenie. Mitt a d Grenzgeb d Med u Chir 1912;25:746.

4. Blalock A, Mason MF, Morgan HJ, et al. Myasthenia Gravis and Tumors of the Thymic Region: Report of a Case in Which the Tumor Was Removed. Ann Surg 1939;110:544-61.

5. Blalock A, Harvey AM, Ford FR, et al. The treatment of myasthenia gravis by removal of the thymus gland Preliminary report. J Amer Med Assoc 1941;117:1529-33.

6. Crile G Jr. Thymectomy through the neck. Surgery 1966;59:213-5.

7. Kirschner PA, Osserman KE, Kark AE. Studies in myasthenia gravis. Transcervical total thymectomy. JAMA 1969;209:906-10.

8. Wenglowski R. Ueber die Halsfisteln und Cysten. Archiv fur Klinishe Chirurgie 1912;98:151-201.

9. Masaoka A, Nagaoka Y, Kotake Y. Distribution of thymic tissue at the anterior mediastinum. Current procedures in thymectomy. J Thorac Cardiovasc Surg 1975;70:747-54.

10. Masaoka A, Monden Y. Comparison of the results of transsternal simple, transcervical simple, and extended thymectomy. Ann N Y Acad Sci 1981;377:755-65.

11. Matell G, Lebram G, Osterman PO, et al. Follow up Comparison of Suprasternal Vs Trans-Sternal Method for Thymectomy in Myasthenia-Gravis. Ann Ny Acad Sci 1981;377:844-5.

12. Wolfe GI, Kaminski HJ, Aban IB, et al. Randomized Trial of Thymectomy in Myasthenia Gravis. N Engl J Med 2016;375:511-22.
13. Wolfe GI, Kaminski HJ, Aban IB, et al. Long-term effect of thymectomy plus prednisone versus prednisone alone in patients with non-thymomatous myasthenia gravis: 2-year extension of the MGTX randomised trial. Lancet Neurol 2019;18:259-68.

14. Fukai I, Funato Y, Mizuno T, et al. Distribution of thymic tissue in the mediastinal adipose tissue. J Thorac Cardiovasc Surg 1991;101:1099-102.

15. Masaoka A, Monden Y, Seike Y, et al. Reoperation after transcervical thymectomy for myasthenia gravis. Neurology 1982;32:83-5.

16. Rosenberg M, Jauregui WO, Devega ME, et al. Recurrence of thymic hyperplasia after thymectomy in myasthenia gravis. Its importance as a cause of failure of surgical treatment. Am J Med 1983;74:78-82.

17. Henze A, Biberfeld P, Christensson B, et al. Failing transcervical thymectomy in myasthenia gravis. An evaluation of transsternal re-exploration. Scand J Thorac Cardiovasc Surg 1984;18:235-8.

18. Rosenberg M, Jauregui WO, Herrera MR, et al. Recurrence of thymic hyperplasia after trans-sternal thymectomy in myasthenia gravis. Chest 1986;89:888-9.

19. Jaretzki A 3rd, Penn AS, Younger DS, et al. "Maximal" thymectomy for myasthenia gravis. Results. J Thorac Cardiovasc Surg 1988;95:747-57.

20. Zielinski M, Kuzdzal J, Staniec B, et al. Extended rethymectomy in the treatment of refractory myasthenia gravis: original video-assisted technique of resternotomy and results of the treatment in 21 patients. Interact Cardiovasc Thorac Surg 2004;3:376-80.

21. Marx A, Rudiger T, Rossner E, et al. Ectopic thymic tissue and ectopic thymic tumors. Pathologe 2018;39:390-7.

22. Moher D, Liberati A, Tetzlaff J, et al. Preferred reporting items for systematic reviews and meta-analyses: the PRISMA statement. BMJ 2009;339:b2535.

23. Jaretzki A 3rd, Wolff M. "Maximal" thymectomy for myasthenia gravis. Surgical anatomy and operative technique. J Thorac Cardiovasc Surg 1988;96:711-6.

24. Ashour M. Prevalence of ectopic thymic tissue in myasthenia gravis and its clinical significance. $\mathrm{J}$ Thorac Cardiovasc Surg 1995;109:632-5.

25. Mineo TC, Pompeo E, Lerut TE, et al. Thoracoscopic thymectomy in autoimmune myasthenia: Results of leftsided approach. Ann Thorac Surg 2000;69:1537-41.

26. Ozdemir N, Kara M, Dikmen E, et al. Predictors of clinical outcome following extended thymectomy in myasthenia gravis. Eur J Cardiothorac Surg 2003;23:233-7.

27. Essa M, El-Medany Y, Hajjar W, et al. Maximal 
thymectomy in children with myasthenia gravis. Eur J Cardiothorac Surg 2003;24:187-9; discussion 190-1.

28. El-Medany Y, Hajjar W, Essa M, et al. Predictors of outcome for myasthenia gravis after thymectomy. Asian Cardiovasc Thorac Ann 2003;11:323-7.

29. Zielinski M, Kuzdzal J, Szlubowski A, et al. Transcervicalsubxiphoid-videothoracoscopic "maximal" thymectomy-operative technique and early results. Ann Thorac Surg 2004;78:404-9; discussion 409-510.

30. Zielinski M, Kuzdzal J, Szlubowski A, et al. Comparison of late results of basic transsternal and extended transsternal thymectomies in the treatment of myasthenia gravis. Ann Thorac Surg 2004;78:253-8.

31. Rea F, Marulli G, Bortolotti L, et al. Experience with the "da Vinci" robotic system for thymectomy in patients with myasthenia gravis: report of 33 cases. Ann Thorac Surg 2006;81:455-9.

32. Ponseti JM, Gamez J, Vilallonga R, et al. Influence of ectopic thymic tissue on clinical outcome following extended thymectomy in generalized seropositive nonthymomatous myasthenia gravis. Eur J Cardiothorac Surg 2008;34:1062-7.

33. Lee CY, Lee JG, Yang WI, et al. Transsternal Maximal Thymectomy is Effective for Extirpation of Cervical Ectopic Thymic Tissue in the Treatment of Myasthenia Gravis. Yonsei Med J 2008;49:987-92.

34. Meacci E, Cesario A, Margaritora S, et al. Thymectomy in myasthenia gravis via original video-assisted inframammary cosmetic incision and median sternotomy: longterm results in 180 patients. Eur J Cardiothorac Surg 2009;35:1063-9; discussion 1069.

35. Pompeo E, Tacconi F, Massa R, et al. Long-term outcome of thoracoscopic extended thymectomy for nonthymomatous myasthenia gravis. Eur J Cardiothorac Surg 2009;36:164-9.

36. Tomulescu V, Sgarbura O, Stanescu C, et al. Ten-year results of thoracoscopic unilateral extended thymectomy performed in nonthymomatous myasthenia gravis. Ann Surg 2011;254:761-5; discussion 765-6.

37. Ambrogi V, Mineo TC. Active ectopic thymus predicts poor outcome after thymectomy in class III myasthenia gravis. J Thorac Cardiovasc Surg 2012;143:601-6.

38. Chen Z, Zuo J, Zou J, et al. Cellular immunity following video-assisted thoracoscopic and open resection for nonthymomatous myasthenia gravis. Eur J Cardiothorac Surg 2014;45:646-51.

39. Marulli G, Schiavon M, Perissinotto E, et al. Surgical and neurologic outcomes after robotic thymectomy in 100 consecutive patients with myasthenia gravis. J Thorac Cardiovasc Surg 2013;145:730-5; discussion 735-6.

40. Ozel A, Akdur PO, Celebi I, et al. Ectopic cervical thymus as a rare cause of pediatric neck mass: the role of ultrasound and MRI in the diagnosis. Case report. Med Ultrason 2015;17:248-51.

41. Cory DA, Cohen MD, Smith JA. Thymus in the superior mediastinum simulating adenopathy: appearance on CT. Radiology 1987;162:457-9.

42. Slovis TL, Meza M, Kuhn JP. Aberrant thymus--MR assessment. Pediatr Radiol 1992;22:490-2.

43. Mineo TC, Ambrogi V, Schillaci O. May positron emission tomography reveal ectopic or active thymus in preoperative evaluation of non-thymomatous myasthenia gravis? J Cardiothorac Surg 2014;9:146.

44. Klimek-Piotrowska W, Mizia E, Kuzdzal J, et al. Ectopic thymic tissue in the mediastinum: limitations for the operative treatment of myasthenia gravis. Eur J Cardiothorac Surg 2012;42:61-5.

45. Mulder DG, White K, Herrmann C Jr. Thymectomy. Surgical procedure for myasthenia gravis. AORN J 1986;43:640-6.

46. Shrager JB, Deeb ME, Mick R, et al. Transcervical thymectomy for myasthenia gravis achieves results comparable to thymectomy by sternotomy. Ann Thorac Surg 2002;74:320-6; discussion 326-7.

47. Mantegazza R, Baggi F, Bernasconi P, et al. Videoassisted thoracoscopic extended thymectomy and extended transsternal thymectomy ( $\mathrm{T}-3 \mathrm{~b})$ in non-thymomatous myasthenia gravis patients: remission after 6 years of follow-up. J Neurol Sci 2003;212:31-6.

48. Weis CA, Aban IB, Cutter G, et al. Histopathology of thymectomy specimens from the MGTX-trial: Entropy analysis as strategy to quantify spatial heterogeneity of lymphoid follicle and fat distribution. Plos One 2018;13:e0197435.

49. Weis CA, Schalke B, Strobel P, et al. Challenging the current model of early-onset myasthenia gravis pathogenesis in the light of the MGTX trial and histological heterogeneity of thymectomy specimens. Ann N Y Acad Sci 2018;1413:82-91.

50. Marticorena Garcia SR, Fischer T, et al. Multifrequency Magnetic Resonance Elastography for the Assessment of Renal Allograft Function. Invest Radiol 2016;51:591-5.

51. Coudray N, Ocampo PS, Sakellaropoulos T, et al. Classification and mutation prediction from non-small cell lung cancer histopathology images using deep learning. Nat Med 2018;24:1559-67. 
52. Mori T, Nomori H, Ikeda K, et al. The distribution of parenchyma, follicles, and lymphocyte subsets in thymus of patients with myasthenia gravis, with special reference to remission after thymectomy. J Thorac Cardiovasc Surg 2007;133:364-8.

53. Roxanis I, Micklem K, McConville J, et al. Thymic myoid cells and germinal center formation in myasthenia gravis; possible roles in pathogenesis. J Neuroimmunol 2002;125:185-97.

54. Okumura M, Inoue M, Kadota Y, et al. Biological implications of thymectomy for myasthenia gravis. Surg Today 2010;40:102-7.

55. Zuckerman NS, Howard WA, Bismuth J, et al. Ectopic $\mathrm{GC}$ in the thymus of myasthenia gravis patients show characteristics of normal GC. Eur J Immunol 2010;40:1150-61.

56. Kuks JB, Oosterhuis HJ, Limburg PC, et al. Antiacetylcholine receptor antibodies decrease after thymectomy in patients with myasthenia gravis. Clinical correlations. J Autoimmun 1991;4:197-211.

57. Kagotani K, Monden Y, Nakahara K, et al. AntiAcetylcholine Receptor Antibody Titer with Extended Thymectomy in Myasthenia-Gravis. J Thorac Cardiovasc
Surg 1985;90:7-12.

58. Olanow CW, Wechsler AS, Roses AD. A prospective study of thymectomy and serum acetylcholine receptor antibodies in myasthenia gravis. Ann Surg 1982;196:11321.

59. Hankins JR, Mayer RF, Satterfield JR, et al. Thymectomy for myasthenia gravis: 14-year experience. Ann Surg 1985;201:618-25.

60. Jaretzki A, Steinglass KM, Sonett JR. Thymectomy in the management of myasthenia gravis. Semin Neurol 2004;24:49-62.

61. Sanders DB, Wolfe GI, Benatar M, et al. International consensus guidance for management of myasthenia gravis: Executive summary. Neurology 2016;87:419-25.

62. Clifford KM, Hobson-Webb LD, Benatar M, et al. Thymectomy may not be associated with clinical improvement in MuSK myasthenia gravis. Muscle Nerve 2019;59:404-10.

63. Kao JC, Milone M, Selcen D, et al. Congenital myasthenic syndromes in adult neurology clinic: A long road to diagnosis and therapy. Neurology 2018;91:e1770-e1777.

64. Keynes G. The results of thymectomy in myasthenia gravis. Br Med J 1949;2:611-6.
Cite this article as: Li F, Tao Y, Bauer G, Elsner A, Li Z, Swierzy M, Englisch J, Meisel A, Ismail M, Rückert JC. Unraveling the role of ectopic thymic tissue in patients undergoing thymectomy for myasthenia gravis. J Thorac Dis 2019;11(9):4039-4048. doi: 10.21037/jtd.2019.08.109 